\title{
Blood Management Strategies in Total Knee Arthroplasty
}

\author{
David Liu, FRACS ${ }^{1}$, Michael Dan, MBBS${ }^{2}$, Sara Martinez Martos, MBBS ${ }^{1}$, and Elaine Beller, BSc MAppStat ${ }^{3}$ \\ ${ }^{1}$ Gold Coast Centre for Bone and Joint Surgery, Queensland; ${ }^{2}$ John Hunter Hospital, New South Wales; ${ }^{3}$ Centre for Research in Evidence-Based Practice Bond \\ University, Queensland, Australia
}

A perioperative blood management program is one of a number of important elements for successful patient care in total knee arthroplasty (TKA) and surgeons should be proactive in its application. The aims of blood conservation are to reduce the risk of blood transfusion whilst at the same time maximizing hemoglobin $(\mathrm{Hb})$ in the postoperative period, leading to a positive effect on outcome and cost. An individualized strategy based on patient specific risk factors, anticipated blood loss and comorbidities are useful in achieving this aim. Multiple blood conservation strategies are available in the preoperative, intraoperative and postoperative periods and can be employed in various combinations. Recent literature has highlighted the importance of preoperative $\mathrm{Hb}$ optimization, minimizing blood loss and evidence-based transfusion guidelines. Given TKA is an elective procedure, a zero allogenic blood transfusion rate should be the aim and an achievable goal.

Keywords: Knee, Arthroplasty, Blood, Conservation strategies

\section{Introduction}

A critical component of successful patient care in total knee arthroplasty (TKA) is a blood management strategy. TKA can result in substantial perioperative blood loss, rendering patients at increased risk of requiring allogenic blood transfusion ${ }^{1,2}$. Total knee and hip arthroplasty and fracture surgery is the number one reason for transfusion in patients undergoing surgery and accounts for $9.8 \%$ of all transfused red blood cell units ${ }^{3}$. Complications of allogenic blood transfusion include the risk of disease transmission, hemolytic reaction, fluid and hemodynamic overload, acute lung injury, coagulopathy, allergic reaction and febrile non-hemolytic reaction ${ }^{4)}$. Allogenic transfusion is associated

Received September 22, 2015; Revised December 21, 2015;

Accepted January 18, 2016

Correspondence to: David Liu, FRACS

Gold Coast Centre for Bone and Joint Surgery, Suite 8A Fred McKay

House, Tugun, Queensland 4224, Australia

Tel: +61-7-5598-0205, Fax: +61-7-5598-0294

E-mail: dliu01@bigpond.com

This is an Open Access article distributed under the terms of the Creative Commons Attribution Non-Commercial License (http://creativecommons.org/licenses/by-nc/4.0/) which permits unrestricted non-commercial use, distribution, and reproduction in any medium, provided the original work is properly cited. with immunomodulation, and an increased incidence of prosthetic infection, ${ }^{5,6)}$. Bierbaum et al. ${ }^{7)}$ reported a transfusion rate of $39 \%$ following TKA, with an increased risk of fluid overload, infection rate and duration of hospitalization in the patients who received allogenic transfusion. Several studies have highlighted the disadvantages of allogenic blood including a negative effect on postoperative complications, length of hospital stay, cost and mortality $^{8-10)}$.

The fundamental aim of blood management is to eliminate the need for allogenic blood whilst at the same time preventing anaemia. Thereby the risk of transfusion is removed, hemoglobin (Hb) status and oxygen carrying capacity is maximized, leading to a positive effect on the patient's recovery and both early and long-term outcomes. Blood management strategies should be individualized, based on patient specific risk factors including preoperative $\mathrm{Hb}$ level, anticipated difficulty of the procedure and expected blood loss, and associated medical comorbidities. $\mathrm{Hb}$ loss in routine primary TKA has been calculated to be $3.8 \mathrm{~g} / \mathrm{dL}^{11}$. The transfusion trigger should be individualized based on the risks and benefits for each patient. Two recently published studies highlighted the benefits of evidence-based, multidisciplinary, multimodal approach to optimizing care in joint replacement patients potentially requiring allogenic transfusion ${ }^{12,13)}$. Both studies 
stressed the importance of optimizing preoperative red cell mass, minimizing perioperative blood loss and being judicious with the threshold for transfusion based on each individual's clinical status. By introducing a multimodal program supported by evidence-based guidelines, transfusion rate was markedly reduced with a significant reduction in complications, 30-day readmission rates, length of hospital stay and mortality. Available blood management strategies can be broadly divided into 3 stages: preoperative optimisation, intraoperative and postoperative protocols ${ }^{14)}$. The spectrum of available modalities is summarized in Table 1.

\section{Preoperative Strategies}

Several studies have highlighted the significant influence of preoperative $\mathrm{Hb}$ on the requirement for transfusion in $\mathrm{TKA}^{11,15)}$. Salido et al. ${ }^{15)}$ demonstrated very few patients with $\mathrm{Hb}$ greater than $150 \mathrm{~g} / \mathrm{L}$ preoperatively required allogenic blood whilst patients with preoperative $\mathrm{Hb}$ level less than $110 \mathrm{~g} / \mathrm{L}$ had a $100 \%$ transfusion rate. Similarly, Pierson et al. ${ }^{11)}$ found an algorithm-based strategy aimed at improving preoperative $\mathrm{Hb}$ level was most effective in reducing transfusion rate. Other risk factors associated with an increased need for transfusion include weight, age greater than 75 years, male gender, hypertension and body mass index less than $27 \mathrm{~kg} / \mathrm{cm}^{2}{ }^{16}$. Whilst many factors are non-modifiable, Pola et al. ${ }^{17)}$ showed more than one risk factor had a compounding effect on transfusion rate. Therefore, in patients with multiple risk factors, it is vitally important to correct anaemia and maximize preoperative red cell mass. Correcting anaemia not only reduces the risk of allogenic transfusion but also has a positive impact on the patient's rehabilitation and functional recovery. Patients with postoperative $\mathrm{Hb}$ between 8 to $10 \mathrm{~g} / \mathrm{dL}$ may not be low enough to warrant transfusion but often feel lethargic, with a higher risk of syncopal episodes, impairing their ability to mobilize and undergo rehabilitation.

In our centre, patients are screened 3 months prior to surgery with full blood count, proceeding to iron studies if the preoperative $\mathrm{Hb}$ is less than $120 \mathrm{~g} / \mathrm{dL}$. Any patient identified with anaemia is referred to the hematology unit for further investigation of the underlying cause and management. A common reason in elderly patients is iron deficiency, as a result of poor dietary intake and occult gastrointestinal bleeding secondary to non-steroidal antiinflammatory drug use. The typical pattern seen in these patients is low $\mathrm{Hb}$ and low ferritin. The parameters measured to investigate iron deficiency are listed in Table 2 with threshold cut-off values.

Options for maximizing $\mathrm{Hb}$ in preparation for surgery include iron supplements and erythropoietin. Iron supplements can either be given orally or intravenously. Both have been shown to be effective, however, oral iron may not be efficacious in patients with malabsorption such as coeliac disease. Another disadvantage of oral iron supplements is the slow effect and therefore it needs to be implemented well in advance of surgery. A cohort

Table 2. Preoperative Iron Studies and Threshold Values for Iron Deficiency in Patients with Preoperative Anaemia, Requiring Correction prior to Total Knee Arthroplasty

\begin{tabular}{lc}
\hline \multicolumn{1}{c}{ Parameter } & Threshold value \\
\hline Hemaglobin $(\mathrm{g} / \mathrm{dL})$ & 12 \\
Hematocrit $(\%)$ & 0.38 \\
Iron $(\mu \mathrm{mol} / \mathrm{L})$ & 5 \\
Total iron binding capacity $(\mu \mathrm{mol} / \mathrm{L})$ & 45 \\
Transferrin saturation $(\%)$ & 20 \\
Ferritin $(\mu \mathrm{g} / \mathrm{L})$ & 50 \\
\hline
\end{tabular}

Table 1. Summary of Blood Management Interventions Available to Reduce Allogenic Transfusion Rates in Total Knee Arthroplasty Patients

\begin{tabular}{llc}
\hline \multicolumn{1}{c}{ Preoperative } & \multicolumn{1}{c}{ Intraoperative } & Postoperative \\
\hline $\begin{array}{l}\text { Correcting anaemia } \\
\text { Investigate cause } \\
\text { Iron supplements } \\
\text { Erythropoietin }\end{array}$ & Acute normovolemic haemodilution & Postoperative cell salvage \\
& Intraoperative cell salvage & Reinfusion drain \\
Preoperative autologous blood donation & Topical fibrin sealant & No drain use \\
& & Tranexamic acid \\
& Tranexamic acid & Oravenous \\
Ceasing antiplatelet and anticoagulant & Intravenous & Topical \\
medications & Oral & Evidence-based individualised trigger \\
& & for allogenic transfusion
\end{tabular}


study of 156 patients treated with ferrous sulfate $256 \mathrm{mg}$ /day for 1 month preoperatively, in with combination vitamin $\mathrm{C}$ which enhances iron absorption, showed a reduced transfusion rate for non-anemic patients ${ }^{18)}$. For our patients with deficient iron stores, the hematologists administer 500-1,000 mg ferritin carboxymaltose as a rapid intravenous infusion over 15 minutes. Dosage depends on duration and severity of iron deficiency. The infusion needs to be given minimum of 3 weeks preoperatively, and is expected to improve the $\mathrm{Hb} 1 \mathrm{~g} / \mathrm{dL}$ over 10 days. We have observed intravenous iron to be more effective than oral supplements (D'Costa E, Unpublished Data). Munoz et al. ${ }^{19)}$ reported a significant increase of $1.8 \mathrm{~g} / \mathrm{dL}$ in $\mathrm{Hb}$ level and $67 \%$ resolution of anaemia using intravenous iron sucrose.

Erythropoietin is a synthetic hormone, stimulating progenitor cells in the bone marrow to differentiate into red blood cells and activating hematopoiesis. Erythropoietin is a powerful agent in correcting anaemia. In a systematic review, Spahn ${ }^{20)}$ showed erythropoietin to be successful in improving mean preoperative $\mathrm{Hb}$ and postoperative $\mathrm{Hb}$ with reduced transfusion rates when combined with iron therapy in patients undergoing TKA. The main disadvantage of erythropoietin is cost and at this stage, its routine use in Australia is not approved in TKA patients unless the patient suffers anaemia secondary to chronic renal failure.

An important element of blood conservation in TKA is limiting blood loss. Patients undergoing TKA frequently take antiplatelet and anticoagulant medications that affect the risk of bleeding. The decision and timing of cessation of antiplatelelet and anticoagulant therapy needs to take into consideration risks of thrombosis versus risk of bleeding. Platelet activation occurs with noncardiac surgery, making myocardial infarction the most common major vascular complication after surgery. Under usual circumstances, warfarin should be discontinued 5 days prior to $\mathrm{TKA}^{21)}$ and recommenced postoperatively when the risks of acute bleeding are believed to be stable. Bridging anticoagulation therapy is commonly used in the interim period with agents such as low molecular heparin, which has a shorter half-life ${ }^{22)}$. There are no clear guidelines or consensus on the optimal bridging therapy for patients on warfarin for conditions such as atrial fibrillation, previous embolic cerebrovascular events or mechanical valve replacement, and further clinical trials are required to clarify the optimal regime.

With regards to aspirin and antiplatelet therapy, its cessation prior to surgery is believed to result in an increased risk of cardiovascular complications and major cardiac events ${ }^{23,24)}$. However, a recent large randomized controlled trial of 10,010 patients including 39\% orthopaedic procedures, comparing aspirin versus placebo with 30-day follow-up after surgery, found conflicting results ${ }^{25)}$. There was no difference in the primary outcome of death or myocardial infarction between the 2 groups, regardless of whether the patient was taking aspirin prior to surgery or not. Aspirin increased the risk of major bleeding compared with placebo. The most common reported site of bleeding was the surgical site in $78.3 \%$ and gastrointestinal tract in $9.3 \%$. The authors concluded aspirin administration before surgery and throughout the early postsurgical period had no significant effect on the rate of composite of death or nonfatal myocardial infarction but increased the risk of major bleeding. We now cease aspirin prior to TKA.

Preoperative autologous donation was previously popular in elective TKA. Allogeneic transfusion rates were reduced from $40 \%-52 \%$ to $3 \%-18 \%$ in the preoperative autologous donor group in two cohort studies ${ }^{26,27}$. However preoperative autologous donation is associated with a high rate of wasted blood and is no longer deemed to be cost effective. There remains the potential for wrong blood being returned to the patient due to clerical errors ${ }^{28,29)}$. The process necessitates the inconvenience of donating blood in advance of scheduled surgery. The use of preoperative autologous blood donation has therefore fallen out of favour and we no longer use it in our TKA patients.

\section{Intraoperative Strategies}

The risk of intraoperative bleeding is influenced by difficulty of the procedure and patient factors such as obesity, comorbidities and bleeding disorders. Meticulous efficient surgical technique with careful dissection, soft tissue handling and bleeding control assists with diminishing blood loss. Maintaining steady blood pressure and normothermia are both recommended in reducing bleeding. Whilst preventing patient hypothermia is accepted to be important in limiting blood loss, we found rigid temperature control is not necessary in a prospective consecutive observational cohort study of patients undergoing primary $\mathrm{TKA}^{30)}$. As long as patient axillary temperature is maintained within the range of $34.7^{\circ} \mathrm{C}-37.8^{\circ} \mathrm{C}$ during the perioperative period, our study demonstrated no effect of patient temperature on transfusion rate or blood loss.

The technique of acute normovolemic hemodilution attempts to achieve a similar effect to preoperative autologous blood donation without the preoperative inconvenience. Blood is collected from the patient in the immediate preoperative period and volume is replaced with colloid or crystalloid fluid. The rationale is surgical blood loss will have a lower hematocrit, and the collected 
whole blood is transfused in the immediate postoperative period, negating the downsides of blood storage. However, the effectiveness of acute normovolemic hemodilution in reducing allogenic transfusion is debatable ${ }^{20)}$. It may be appropriate in selected cases where blood cross matching is difficult due to the presence of antibodies however we do not recommend its routine use.

Perioperative red cell salvage collects blood lost during the operative procedure and immediate postoperative period, and returns the blood to the patient. This technique has several advantages over preoperative autologous donation and acute normovolemic hemodilution. Perioperative red cell salvage reinfuses fresh blood, thereby avoiding problems associated with storage, seen with autologous predonation and allogeneic blood. This translates to more efficacious oxygen carrying capacity with a higher mean erythrocyte viability ${ }^{31)}$ and increased preservation of 2-3 diphosphoglycerate ${ }^{32}$. Red cell salvage also incorporates washing the blood loss volume. Washing the blood removes biochemical, cellular and non-cellular debris ${ }^{31)}$. Unwashed cell salvage is associated with adverse postoperative effects due to the presence of cytokines including hypotension, hyperthermia, increased postoperative bleeding and non-cardiogenic pulmonary edema $^{33,34)}$. We have been using intraoperative red cell salvage for primary and revision TKA, with success in reducing allogenic transfusion requirement (Dan $M$, Unpublished Data). The efficacy of cell salvage in TKA in our cohort compared to previously published studies ${ }^{35-37)}$ is outlined in Table 3 . We concluded perioperative red cell salvage reduces but does not eliminate the need for allogenic blood. The effectiveness of intraoperative red cell salvage is dependent on preoperative $\mathrm{Hb}$ and hematocrit of blood lost and actual blood loss volume, which in turn determine the ability to return red cells. We believe intraoperative red cell salvage is most effective in patients with preoperative $\mathrm{Hb}$ between 120 to $150 \mathrm{~g} / \mathrm{dL}$, further emphasizing the importance of correcting preoperative $\mathrm{Hb}$ above $120 \mathrm{~g} / \mathrm{dL}$ prior to TKA. Above $150 \mathrm{~g} /$ $\mathrm{dL}$, cell salvage is not usually required as allogenic transfusion rate is negligible.

Table 3. Allogenic Transfusion Rate Using Autologous Reinfusion of Salvaged Blood Cells in Randomized Controlled Trials and Cohort Studies on Total Knee Arthroplasty

\begin{tabular}{lc}
\hline \multicolumn{1}{c}{ Study } & Allogenic transfusion rate (\%) \\
\hline Dan M & \\
Shenolikar et al. & \\
(5) & 11.9 \\
Thomas et al. $^{36)}$ & 16.0 \\
Munoz et al. $^{37)}$ & 7.0 \\
\hline
\end{tabular}

${ }^{\text {a) Unpublished data. }}$
Topical fibrin sealant, composed of fibrinogen and thrombin, mimics the final step of coagulation cascade when mixed together during the application process. Randelli et al. ${ }^{38)}$ performed a randomized trial of topical fibrin versus control group in TKA and found no difference in $\mathrm{Hb}$ levels, postoperative decrease in $\mathrm{Hb}$, drainage or mean total blood loss. In particular, the transfusion rate was $32.3 \%$ in the control group compared with $25.8 \%$ in the fibrin group, with no significant difference. The authors concluded topical application of fibrin sealant was not effective in reducing perioperative blood loss in TKA. Another randomized study comparing topical fibrin spray to intravenous tranexamic acid (TXA) demonstrated comparable reduction in blood loss but the cost of the fibrin spray was significantly greater ${ }^{39)}$.

\section{Postoperative Strategies}

The routine use of intra-articular wound drainage in TKA has been shown to increase blood transfusion requirement ${ }^{40)}$. This needs to be balanced with the reported increased risk of persistent ooze, bruising and hematoma formation ${ }^{41)}$. Evidence for use of an intra-articular drain in TKA therefore remains inconclusive and very much an individual decision based on surgeon preference.

Postoperative reinfusion drains are commonly employed in TKA and previous investigations suggest reduction in allogeneic transfusion rate. A meta-analysis by Huet et al. ${ }^{33)}$ showed a relative risk reduction of 0.35 for allogeneic transfusion need with reinfusion drains. Zacharopoulos et al. ${ }^{42)}$ performed a prospective randomized controlled trial with reinfusion drains, demonstrating a decrease in allogenic blood transfusion. In contrast, Hazarika et al. ${ }^{43)}$ showed reinfusion drains had no significant benefit with the downside of additional cost. Reinfusion drains carry the potential for transfusion reaction, as the unwashed blood contains fibrin degradation products and other potential contaminants ${ }^{44,45)}$. The drained blood needs to be reinfused with 6 hours of commencement to avoid the potential for hemolysis. We no longer use reinfusion drains, as the cost does not seem to be justified, especially with the increasing use of TXA in reducing postoperative blood loss.

A multitude of publications have highlighted the use and benefits of antifibrinolytic agents. TXA is one such agent, being a synthetic plasminogen-activator inhibitor, showing both clinical efficacy and an acceptable safety profile. TXA inhibits the activation of plasminogen to plasmin by blocking the lysine binding sites of plasminogen to fibrin. The result is decrease proteolytic action on fibrin monomers and fibrinogen, leading to clot sta- 
bilization $^{46)}$. The use of TXA in primary TKA is associated with reduced transfusion rates, increased discharge to home, and reduced $\operatorname{costs}^{477}$.

TXA has desirable features of ease of administration, minimal effect on operative procedure workflow, and extremely low cost as a generic medicine. Intravenous TXA has been demonstrated to significantly reduce the amount of blood loss and blood transfusion requirements without an increase in venous thromboembolic risk in multiple studies for TKA ${ }^{48,49)}$.

There is however no clear consensus on ideal dosage, timing, frequency and route of administration for TXA in TKA. The current recommendation for intravenous use is 10 to $15 \mathrm{mg} / \mathrm{kg}$ as a single dose. However significant heterogeneity exists in currently available studies, with doses ranging from 700 to $10,500 \mathrm{mg}$ and often with multiple dosages. Oral TXA has shown similar effectiveness to intravenou ${ }^{50}$. Several contra-indications preclude the use of intravenous TXA at the time of surgery, including renal insufficiency, history of previous deep venous thrombosis, cerebrovascular and cardiac disease. One study reported $28 \%$ of patients were contraindicated to intravenous TXA ${ }^{51)}$ and in these patients topical administration may be more appropriate due to delay in systemic absorption after application into the knee. Intra-articular application limits systemic exposure and maximizes drug concentration and activity directly at the site of bleeding. Wong et al. ${ }^{52)}$ proved the efficacy of intra-articular TXA in a doubleblind, placebo-controlled randomized trial in TKA. The authors demonstrated a significant difference in $\mathrm{Hb}$ reduction and blood loss using $3.0 \mathrm{~g}$ of TXA in $100 \mathrm{~mL}$ of normal saline compared to $1.5 \mathrm{~g}$ of TXA and placebo, with no difference in thromboembolic complications. Plasma levels of TXA following topical administration were $70 \%$ less than an equivalent intravenous dose. More recently, a retrospective study found intra-articular and pericapsular injection of TXA after capsular closure resulted in a transfusion rate reduction from $17.5 \%$ to $5.5 \%$ as well as a significantly higher postoperative $\mathrm{Hb}$ in the TXA group ${ }^{51)}$. Alshryda et al. ${ }^{53)}$ performed a systematic review and meta-analysis showing topical TXA to significantly reduce the rate of blood transfusion and was safe. Topical dose in the analysed studies ranged from 250 to $3,000 \mathrm{mg}$.

A number of studies have directly compared intravenous TXA with topical TXA demonstrating the efficacy and safety of topical administration in TKA ${ }^{54-56}$. Both Patel et al. ${ }^{51}$, using a single intravenous dose, and Soni et al. ${ }^{57)}$, using a 3 dose intravenous regimen, concluded topical TXA had similar efficacy to intravenous TXA in terms of perioperative change in $\mathrm{Hb}$, lowest postoperative $\mathrm{Hb}$, total drain output and transfusion rate, and no increase in complications in randomized prospective studies. In a study comparing 3 methods of administration in TKA, single dose intravenous TXA was more effective than topical and intraarticular TXA injected via the drain in reducing $\mathrm{Hb}_{\text {drop }}{ }^{58}$. Local administration through the drain yielded least blood drainage postoperatively compared to intravenous and topical application, with $80 \%$ reduction of drainage volume compared to $45 \%$ and $18 \%$, respectively. In contrast, Maniar et al. ${ }^{59)}$ found single intravenous dose did not give effective results. A 3-dose regimen of preoperative, intraoperative and postoperative doses of $10 \mathrm{mg} /$ $\mathrm{kg}$ produced maximum effective reduction of drain loss and total blood loss in TKA. The authors concluded a preoperative dose prior to tourniquet inflation was important to inhibit the activation of the fibrinolysis cascade.

Our preference in TKA is to use topical TXA, with no patients contraindicated to its use. $3.0 \mathrm{~g}$ of TXA combined with $20 \mathrm{~mL}$ normal saline is administered to the operative site after prosthesis cementation and final washout for 5 minutes. After 5 minutes, any residual fluid is removed and wound closure performed without further lavage or intra-articular drain insertion.

\section{Appropriate Transfusion Guidelines}

Another principal arm of effective blood management is to restrict allogenic transfusion to patients meeting well-established transfusion criteria. Adherence to evidence-based transfusion guidelines and utilization of appropriate transfusion triggers is the key element in achieving this. The recommendations for a restrictive transfusion protocol include transfusion in patients with $\mathrm{Hb}<7 \mathrm{~g} / \mathrm{dL}, \mathrm{Hb}<8 \mathrm{~g} / \mathrm{dL}$ in setting of cardiac disease, or specific patient situations where additional oxygen carrying capacity is needed. Transfusion of a single unit of packed red blood cells at a time is advised ${ }^{12}$.

The blood management strategy algorithm used in our hospital is shown in Fig. 1.

\section{Conclusions}

A blood management program in TKA aims to reduce allogenic transfusion rate and its associated risks, whilst at the same time maximizing $\mathrm{Hb}$ level and oxygen carrying capacity in the postoperative period. Effective blood conservation encompasses optimizing preoperative red cell mass, salvaging blood lost during the perioperative period, minimsing blood loss with hemostatic measures and individualizing the transfusion trigger according to the patient's clinical status and medical comorbidities. We use a combination of preoperative intravenous iron infusion, intra- 


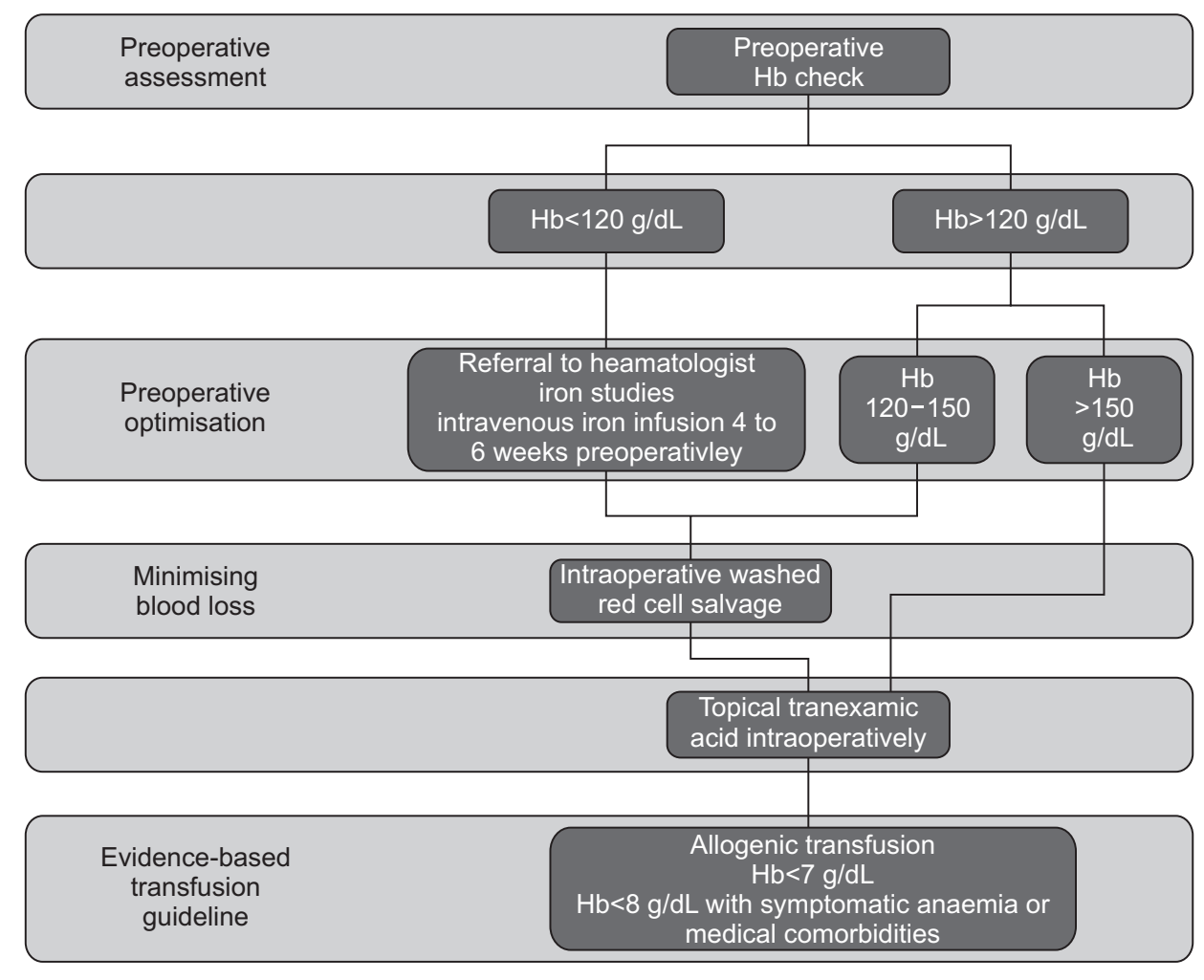

Fig. 1. Blood conservation algorithm used in our unit for total knee arthroplasty. $\mathrm{Hb}$ : hemoglobin. operative red cell salvage, and topical TXA. A proactive approach to blood management will lead to a positive effect on early and long-term outcomes and greater success in care of TKA patients.

\section{Conflict of Interest}

No potential conflict of interest relevant to this article was reported.

\section{References}

1. Eubanks JD. Antifibrinolytics in major orthopaedic surgery. J Am Acad Orthop Surg. 2010;18:132-8.

2. Noticewala MS, Nyce JD, Wang W, Geller JA, Macaulay W. Predicting need for allogeneic transfusion after total knee arthroplasty. J Arthroplasty. 2012;27:961-7.

3. Shortt J, Polizzotto MN, Waters N, Borosak M, Moran M, Comande M, Devine A, Jolley DJ, Wood EM. Assessment of the urgency and deferability of transfusion to inform emergency blood planning and triage: the Bloodhound prospective audit of red blood cell use. Transfusion. 2009;49:2296303.

4. Goodnough LT, Shuck JM. Risks, options, and informed consent for blood transfusion in elective surgery. Am J Surg.
1990;159:602-9.

5. Newman ET, Watters TS, Lewis JS, Jennings JM, Wellman SS, Attarian DE, Grant SA, Green CL, Vail TP, Bolognesi MP. Impact of perioperative allogeneic and autologous blood transfusion on acute wound infection following total knee and total hip arthroplasty. J Bone Joint Surg Am. 2014;96: 279-84.

6. Innerhofer P, Klingler A, Klimmer C, Fries D, Nussbaumer W. Risk for postoperative infection after transfusion of white blood cell-filtered allogeneic or autologous blood components in orthopedic patients undergoing primary arthroplasty. Transfusion. 2005;45:103-10.

7. Bierbaum BE, Callaghan JJ, Galante JO, Rubash HE, Tooms RE, Welch RB. An analysis of blood management in patients having a total hip or knee arthroplasty. J Bone Joint Surg Am. 1999;81:2-10.

8. Hebert PC, Wells G, Tweeddale M, Martin C, Marshall J, Pham B, Blajchman M, Schweitzer I, Pagliarello G. Does transfusion practice affect mortality in critically ill patients? Transfusion Requirements in Critical Care (TRICC) Investigators and the Canadian Critical Care Trials Group. Am J Respir Crit Care Med. 1997;155:1618-23.

9. Bernard AC, Davenport DL, Chang PK, Vaughan TB, Zwischenberger JB. Intraoperative transfusion of $1 \mathrm{U}$ to $2 \mathrm{U}$ 
packed red blood cells is associated with increased 30-day mortality, surgical-site infection, pneumonia, and sepsis in general surgery patients. J Am Coll Surg. 2009;208:931-7.

10. Bower WF, Jin L, Underwood MJ, Lam YH, Lai PB. Perioperative blood transfusion increases length of hospital stay and number of postoperative complications in non-cardiac surgical patients. Hong Kong Med J. 2010;16:116-20.

11. Pierson JL, Hannon TJ, Earles DR. A blood-conservation algorithm to reduce blood transfusions after total hip and knee arthroplasty. J Bone Joint Surg Am. 2004;86:1512-8.

12. Loftus TJ, Spratling L, Stone BA, Xiao L, Jacofsky DJ. A patient blood management program in prosthetic joint arthroplasty decreases blood use and improves outcomes. J Arthroplasty. 2016;31:11-4.

13. Holt JB, Miller BJ, Callaghan JJ, Clark CR, Willenborg MD, Noiseux NO. Minimizing blood transfusion in total hip and knee arthroplasty through a multimodal approach. J Arthroplasty. 2016;31:378-82.

14. Krebs V, Hozack WJ, Callaghan JJ, Bohannon Mason J, Mont M, Parvizi J. Eliminating transfusion in primary joint arthroplasty-an achievable goal. J Arthroplasty. 2014;29:1511.

15. Salido JA, Marin LA, Gomez LA, Zorrilla P, Martinez C. Preoperative hemoglobin levels and the need for transfusion after prosthetic hip and knee surgery: analysis of predictive factors. J Bone Joint Surg Am. 2002;84:216-20.

16. Bong MR, Patel V, Chang E, Issack PS, Hebert R, Di Cesare PE. Risks associated with blood transfusion after total knee arthroplasty. J Arthroplasty. 2004;19:281-7.

17. Pola E, Papaleo P, Santoliquido A, Gasparini G, Aulisa L, De Santis E. Clinical factors associated with an increased risk of perioperative blood transfusion in nonanemic patients undergoing total hip arthroplasty. J Bone Joint Surg Am. 2004; 86:57-61.

18. Cuenca J, Garcia-Erce JA, Martinez F, Cardona R, PerezSerrano L, Munoz M. Preoperative haematinics and transfusion protocol reduce the need for transfusion after total knee replacement. Int J Surg. 2007;5:89-94.

19. Munoz M, Garcia-Erce JA, Cuenca J, Bisbe E, Naveira E; AWGE (Spanish Anaemia Working Group). On the role of iron therapy for reducing allogeneic blood transfusion in orthopaedic surgery. Blood Transfus. 2012;10:8-22.

20. Spahn DR. Anemia and patient blood management in hip and knee surgery: a systematic review of the literature. Anesthesiology. 2010;113:482-95.

21. Arthroplasty Society of Australia. Guidelines for venous thrombotic episode prophylaxis for hip and knee arthroplas- ty [Internet]. Sydney: Australian Orthopaedic Association; 2010 [cited 2010 Sep 22]. Available from: https://www.aoa. org.au/.

22. Bruce W, Campbell D, Daly D, Isbister J. Practical recommendations for patient blood management and the reduction of perioperative transfusion in joint replacement surgery. ANZ J Surg. 2013;83:222-9.

23. Burger W, Chemnitius JM, Kneissl GD, Rucker G. Low-dose aspirin for secondary cardiovascular prevention - cardiovascular risks after its perioperative withdrawal versus bleeding risks with its continuation: review and meta-analysis. J Intern Med. 2005;257:399-414.

24. Oscarsson A, Gupta A, Fredrikson M, Jarhult J, Nystrom M, Pettersson E, Darvish B, Krook H, Swahn E, Eintrei C. To continue or discontinue aspirin in the perioperative period: a randomized, controlled clinical trial. Br J Anaesth. 2010;104: 305-12.

25. Devereaux PJ, Mrkobrada M, Sessler DI, Leslie K, AlonsoCoello P, Kurz A, Villar JC, Sigamani A, Biccard BM, Meyhoff CS, Parlow JL, Guyatt G, Robinson A, Garg AX, Rodseth RN, Botto F, Lurati Buse G, Xavier D, Chan MT, Tiboni M, Cook D, Kumar PA, Forget P, Malaga G, Fleischmann E, Amir M, Eikelboom J, Mizera R, Torres D, Wang CY, VanHelder T, Paniagua P, Berwanger O, Srinathan S, Graham M, Pasin L, Le Manach Y, Gao P, Pogue J, Whitlock R, Lamy A, Kearon C, Baigent C, Chow C, Pettit S, Chrolavicius S, Yusuf $S$; POISE-2 Investigators. Aspirin in patients undergoing noncardiac surgery. N Engl J Med. 2014;370:1494-503.

26. Cushner FD, Scott WN, Scuderi G, Hill K, Insall JN. Blood loss and transfusion rates in bilateral total knee arthroplasty. J Knee Surg. 2005;18:102-7.

27. Biesma DH, Marx JJ, Kraaijenhagen RJ, Franke W, Messinger D, van de Wiel A. Lower homologous blood requirement in autologous blood donors after treatment with recombinant human erythropoietin. Lancet. 1994;344:367-70.

28. Cohen JA, Brecher ME. Preoperative autologous blood donation: benefit or detriment? A mathematical analysis. Transfusion. 1995;35:640-4.

29. Birkmeyer JD, Goodnough LT, AuBuchon JP, Noordsij PG, Littenberg B. The cost-effectiveness of preoperative autologous blood donation for total hip and knee replacement. Transfusion. 1993;33:544-51.

30. Dan M, Martos SM, Beller E, Jones P, Randle R, Liu D. Blood loss in primary total knee arthroplasty: body temperature is not a significant risk factor: a prospective, consecutive, observational cohort study. J Orthop Surg Res. 2015;10:97. 
31. Munoz Gomez M, Sanchez Arrieta Y, Garcia Vallejo JJ, Merida de la Torre FJ, Ruiz Romero de la Cruz MD, Eloy-Garcia JM. Pre and post-operative autotransfusion: a comparative study of hematology, biochemistry and red cell metabolism in pre-donated blood and blood from post-operative surgical drainage. Sangre (Barc). 1999;44:443-50.

32. Noon GP. Intraoperative autotransfusion. Surgery. 1978;84: 719-21.

33. Huet C, Salmi LR, Fergusson D, Koopman-van Gemert AW, Rubens F, Laupacis A. A meta-analysis of the effectiveness of cell salvage to minimize perioperative allogeneic blood transfusion in cardiac and orthopedic surgery: International Study of Perioperative Transfusion (ISPOT) Investigators. Anesth Analg. 1999;89:861-9.

34. Faught C, Wells P, Fergusson D, Laupacis A. Adverse effects of methods for minimizing perioperative allogeneic transfusion: a critical review of the literature. Transfus Med Rev. 1998;12:206-25.

35. Shenolikar A, Wareham K, Newington D, et al. Cell salvage auto transfusion in total knee replacement surgery. Transfus Med 1997;7:277-80.

36. Thomas D, Wareham K, Cohen D, et al. Autologous blood transfusion in total knee replacement surgery. Br J Anaesth 2001;86:669-73.

37. Munoz M, Ariza D, Garceran MJ, et al. Benefits of postoperative shed blood reinfusion in patients undergoing unilateral total knee replacement. Arch Orthop Trauma Surg 2005; 125:385-9.

38. Randelli F, D’Anchise R, Ragone V, Serrao L, Cabitza P, Randelli P. Is the newest fibrin sealant an effective strategy to reduce blood loss after total knee arthroplasty? A randomized controlled study. J Arthroplasty. 2014;29:1516-20.

39. Molloy DO, Archbold HA, Ogonda L, McConway J, Wilson RK, Beverland DE. Comparison of topical fibrin spray and tranexamic acid on blood loss after total knee replacement: a prospective, randomised controlled trial. J Bone Joint Surg Br. 2007;89:306-9.

40. Parker MJ, Livingstone V, Clifton R, McKee A. Closed suction surgical wound drainage after orthopaedic surgery. Cochrane Database Syst Rev. 2007;(3):CD001825.

41. Kumar S, Penematsa S, Parekh S. Are drains required following a routine primary total joint arthroplasty? Int Orthop. 2007;31:593-6.

42. Zacharopoulos A, Apostolopoulos A, Kyriakidis A. The effectiveness of reinfusion after total knee replacement: a prospective randomised controlled study. Int Orthop. 2007;31:
303-8.

43. Hazarika S, Bhattacharya R, Bhavikatti M, Dawson M. A comparison of post-op haemoglobin levels and allogeneic blood transfusion rates following total knee arthroplasty without drainage or with reinfusion drains. Acta Orthop Belg. 2010;76:74-8.

44. Dalen T, Bengtsson A, Brorsson B, Engstrom KG. Inflammatory mediators in autotransfusion drain blood after knee arthroplasty, with and without leucocyte reduction. Vox Sang. 2003;85:31-9.

45. Hansen E, Hansen MP. Reasons against the retransfusion of unwashed wound blood. Transfusion. 2004;44(12 Suppl): 45S-53S.

46. Dunn CJ, Goa KL. Tranexamic acid: a review of its use in surgery and other indications. Drugs. 1999;57:1005-32.

47. Tuttle JR, Ritterman SA, Cassidy DB, Anazonwu WA, Froehlich JA, Rubin LE. Cost benefit analysis of topical tranexamic acid in primary total hip and knee arthroplasty. J Arthroplasty. 2014;29:1512-5.

48. Yang ZG, Chen WP, Wu LD. Effectiveness and safety of tranexamic acid in reducing blood loss in total knee arthroplasty: a meta-analysis. J Bone Joint Surg Am. 2012;94:11539.

49. Alshryda S, Sarda P, Sukeik M, Nargol A, Blenkinsopp J, Mason JM. Tranexamic acid in total knee replacement: a systematic review and meta-analysis. J Bone Joint Surg Br. 2011;93:1577-85.

50. Kagoma YK, Crowther MA, Douketis J, Bhandari M, Eikelboom J, Lim W. Use of antifibrinolytic therapy to reduce transfusion in patients undergoing orthopedic surgery: a systematic review of randomized trials. Thromb Res. 2009; 123:687-96.

51. Patel JN, Spanyer JM, Smith LS, Huang J, Yakkanti MR, Malkani AL. Comparison of intravenous versus topical tranexamic acid in total knee arthroplasty: a prospective randomized study. J Arthroplasty. 2014;29:1528-31.

52. Wong J, Abrishami A, El Beheiry H, Mahomed NN, Roderick Davey J, Gandhi R, Syed KA, Muhammad Ovais Hasan S, De Silva Y, Chung F. Topical application of tranexamic acid reduces postoperative blood loss in total knee arthroplasty: a randomized, controlled trial. J Bone Joint Surg Am. 2010;92: 2503-13.

53. Alshryda S, Sukeik M, Sarda P, Blenkinsopp J, Haddad FS, Mason JM. A systematic review and meta-analysis of the topical administration of tranexamic acid in total hip and knee replacement. Bone Joint J. 2014;96:1005-15. 
54. Seo JG, Moon YW, Park SH, Kim SM, Ko KR. The comparative efficacies of intra-articular and IV tranexamic acid for reducing blood loss during total knee arthroplasty. Knee Surg Sports Traumatol Arthrosc. 2013;21:1869-74.

55. Wind TC, Barfield WR, Moskal JT. The effect of tranexamic acid on blood loss and transfusion rate in primary total knee arthroplasty. J Arthroplasty. 2013;28:1080-3.

56. Ishida K, Tsumura N, Kitagawa A, Hamamura S, Fukuda K, Dogaki Y, Kubo S, Matsumoto T, Matsushita T, Chin T, Iguchi T, Kurosaka M, Kuroda R. Intra-articular injection of tranexamic acid reduces not only blood loss but also knee joint swelling after total knee arthroplasty. Int Orthop. 2011; 35:1639-45.
57. Soni A, Saini R, Gulati A, Paul R, Bhatty S, Rajoli SR. Comparison between intravenous and intra-articular regimens of tranexamic acid in reducing blood loss during total knee arthroplasty. J Arthroplasty. 2014;29:1525-7.

58. Sarzaeem MM, Razi M, Kazemian G, Moghaddam ME, Rasi AM, Karimi M. Comparing efficacy of three methods of tranexamic acid administration in reducing hemoglobin drop following total knee arthroplasty. J Arthroplasty. 2014; 29:1521-4.

59. Maniar RN, Kumar G, Singhi T, Nayak RM, Maniar PR. Most effective regimen of tranexamic acid in knee arthroplasty: a prospective randomized controlled study in 240 patients. Clin Orthop Relat Res. 2012;470:2605-12. 